\title{
The Preferred Work Paradigm for Generation Y in the Hotel Industry: A Case Study of the International Tourism and Hospitality International Programme, Thailand
}

\author{
Nate-tra Dhevabanchachai ${ }^{1} \&$ Kaewta Muangasame ${ }^{2}$ \\ ${ }^{1}$ Lecturer, Tourism and Hospitality Management Division, and General Manager, Salaya Pavilion Hotel and \\ Training Center, Mahidol University International College, Thailand \\ ${ }^{2}$ Lecturer, Tourism and Hospitality Management Division, Mahidol University International College, Thailand \\ Correspondence: Kaewta Muangasame, Tourism and Hospitality Management Division, Mahidol University \\ International College, Thailand. Tel: 66-814-914-230. E-mail: kaewta.mua@mahidol.ac.th
}

\author{
Received: July 28, 2013 Accepted: September 2, $2013 \quad$ Online Published: September 26, 2013 \\ doi:10.5539/ies.v6n10p27 URL: http://dx.doi.org/10.5539/ies.v6n10p27
}

\begin{abstract}
It is well known that hospitality work is physically demanding and involves mental stress and, at times, an un-competitive compensation package. This has resulted in a high employee turnover rate in recent years. Staff retention is thus a challenge, especially for employees belonging to Generation Y (Gen Y). The situation in Thailand is not different, especially with respect to Gen Y. This article aims to identify the ideas and perceptions held by Gen Y undergraduates who are currently being educated in the field of tourism and hospitality and whose education will possibly lead them Gen to seek long-term employment in the hotel industry. In order to identify the influential factors, the researchers aim to obtain maximum information, views and thoughts from research purposive respondents in this study; thus, qualitative research using an inductive approach involving a focus group discussion methodology was selected. 66 Gen Y students who are studying the Tourism and Hospitality Management programme from the first International College in Thailand participated in this study. The results suggest that Gen Y students share similar views on the influential factors to work effectively. They identified five key factors: effective leaders, a friendly environment, good pay and benefits, a flexible policy and culture and great facilities. The result details allow an understanding of the conditions and requirements for practitioners and researchers who are interested in studying Gen Y in the hotel industry.
\end{abstract}

Keywords: working conditions in the hospitality industry, Generation Y, Generational Y's characteristics, Thailand, international programme

\section{Introduction}

The hospitality industry is a people industry: it has been consistently emphasised that the human element is vital to product and service delivery within the industry (Crosby and Stephen, 1987; Gronroos, 1990, Parasuraman et al., 1985, Solomon et al 1985); people are the core feature of operations in the hospitality industry. The tourism and hospitality field has become important worldwide and is a fast growing industry in many countries. However, the industry faces the significant issue of employee turnover (Bares, 2011). Because every time an employee resigns, a replacement must be recruited, selected and trained there is great concern within the hospitality industry about the high turnover of employees. A great deal of effort with respect to human resource management is needed to minimize the turnover impact. (Samuel and Chinpunza, 2009).

A Gen Y workforce has recently entered the market and is now a major driving factor not only in the hospitality industry but for most businesses. At $41 \%$ of the general working population, Gen Y ranked as contributing the highest percentage of the general working population when compared to other generations (Benckendorff et al, 2010). Furthermore, McCrindle (2010) has stated that Gen Y most probably contributes the highest percentage of the total workforce in the hospitality industry. Therefore, it is necessary for employers to pay attention to Gen $\mathrm{Y}$ employees who are becoming the majority in every organisation.

Hinkin and Tracey (2000) have stated that the working conditions in the hospitality industry are demanding, with long hours, tight schedules, and a high level of pressure from customers, colleagues and the work itself. Sinnithithavor (2010) investigated Gen Y's work behaviour and found that Gen Y are highly technologically 
adept, do not prefer many rules and regulations in the workplace, make fast decisions with respect to resignation if they are dissatisfied, are extremely confident, expect a high salary at the entry level, and expect fast promotion; they love freedom and like to be empowered at work; in the meantime, they prefer mobility and dislike routine work. Members of Gen Y whose managers are members of the baby-boomer generation view baby-boomers as antique, not up-to-date and as not very effective in terms of management. They therefore do not value seniority. However, they do like to be recognised. They are well educated as many members of Gen Y hope to gain further degrees as they believe a good education and degrees are factors which create a competitive advantage (Thamma, 2009).

It seems that the working conditions in the hospitality industry do not match Gen Y's characteristics, despite that an increased workforce from Gen Y is needed. At the same time, between 1992 and 2010 the number of available bedrooms in the Thai hotel industry increased from 130,000 to 384,000 . In addition, competition in the Thai hotel industry has increased as more international players have penetrated the market (Thai Hotels Association, 1991). Although the Thai hospitality market is a tough one and has been affected by the economic crisis, and is increasingly seeking new income, the hospitality industry is still a focal channel of revenue creation for Thailand (Boon-itt and Chomvong, 2010). The Thai hotel industry will therefore require Gen Y to take a lead in the future.

This research aims to explore the ideas and perceptions held by Gen Y undergraduates who are currently being educated in the field of tourism and hospitality and whose education will possibly lead them to seek long-term employment in the hotel industry. The researchers studied two groups of students: one group who are engaged in their first hotel internship (the inexperienced group) and another group who have already completed their first hotel internship (the experienced group).

In this research, the researchers carried out research sampling at Mahidol University International College (MUIC), a prestigious international college. MUIC is the first educational institution in Thailand to have initiated an international tourism and hospitality programme. MUIC also has a well-established in-house hotel training centre, Salaya Pavilion Hotel and Training Center (SPH), which provides practical compulsory hotel internships to students who are enrolled in the tourism and hospitality programme.

The objectives of this research are as follows:

- To explore the influential factors that encourage Gen Y to work more effectively and to remain for a longer period in the hotel industry.

- To explore and identify whether there are differences with regard to those influential factors with respect to the two groups of students (experienced and inexperienced).

The results of this research will be meaningful to academics who are responsible for mentally preparing students for possible work conditions before their internships, or before they first enter the hotel industry. Moreover, hotel practitioners can use the results of this research to adjust their plans for working with Gen Y so as to sustain Gen Y associates who are creative, smart, and technologically adept (Asisonthisakul, 2005).

\section{Literature Review}

\subsection{Working Conditions and Required Competencies in the Hotel Industry}

Hinkin and Tracey (2000) have stated that employees in the hospitality industry resign because of dissatisfaction with the existing job conditions rather than as a result of identifying opportunities to commence a new job. Hospitality work is widely known to be demanding: there are long working hours, tight work schedules, repetitive or routine, high pressure as a result of customer demands and standards; at the same time workers receive low pay compared to workers in many other industries; there is also a lack of career advancement opportunities.

Additionally, Kusluvan (2000) has found that physical working conditions in the hotel industry are perceived unfavourably, especially with respect to dormitories, bathrooms, dining areas, and employee lockers: these they are all perceived to be unsatisfactory. There is also a risk of accidents in the workplace and the working environment is noisy. Ineffective managers and possible conflicts among coworkers arising from the need for wide ranging employee coordination are also negative factors.

In recently years, the hospitality industry has seen fierce competition. Therefore, to service guest demands, there has been increasing and significant adaptations as well as changes in standardisation, quality and service policies. This has resulted in higher demands with regard to improvements in staff effort, knowledge, skills and abilities, either through company training or self-learning. The hoteliers many times work under the condition of "change" 
at all time. Furthermore, most jobs have been altered as a result of technology and downsizing. Employees in the hotel industry have to learn more and do more compared to the past. Labour shortages and/or a reduced number of employees have meant that competition for qualified employees has only increased. Employees' stress at work has also increased (Hinkin and Tracey, 2000).

As has been said, working conditions in the hotel industry is both physically and mentally challenging. Other factors include: caring for different needs as a result of a varied guest profile; coordinating with coworkers from different departments and across different work settings; interacting with different levels of supervisors and management in respect of various instructions and requirements; dealing with information manually and with the use of technology; handling heavy equipment and machinery; learning, and adapting to, new ways of work, standardisation, and policies etc.

The working conditions in the hospitality industry are difficult and complex. Some of the fundamental competencies required in the hotel industry are as follows:

1) Emotional positivity; friendly and joyful behaviour (a welcoming employee cannot be replaced by any form of technology).

2) Flexibility, tolerance, amiability and responsibility (Ritzer, 1993).

3) Social and interpersonal skills.

4) Language proficiency: English especially is a prerequisite for hospitality work in countries like Thailand, as well as wider cultural communication.

5) Entrepreneurial and management skills.

6) Multi-tasking skills.

7) Creativity and information processing skills (Mistillis and Daniele, 2000).

8) Ability with numbers and information technology.

9) Working with others and self-learning.

10) A focus on customer service: handling difficult people, problem solving.

11) Technical, generic and aesthetic competencies.

12) Initiative, ability to adapt and willingness to learn (Warhurst et al, 2000).

The great challenges in the working environment and the skills required mean that hotel work requires a person who calls him or herself a "hotelier" to take on responsibility and self-development in order to succeed in their work (Hinkin and Tracey, 2000).

\subsection{Different Work Values of Different Generations}

There has been an increase in the diversity of the hospitality workforce, with respect to gender, ethnicity, race and generation. It has been identified that there is a large degree of conflict, resentment and misunderstanding between old and young employees; this is an increasing a problem in the hotel industry (Zemke et al, 1989). There are differences between, and similarities among, baby-boomers (born between 1946 and 1964), those belonging to Generation X (born between 1965 and 1977), and Gen Y (born after 1977.

Smola and Sutton's (2002) findings suggest that baby-boomers see work as the most important thing in life and Generation X feels that hard work can turn one into a better person. Chen and Choi (2008) have found that all three generations expect a good balance in life, but that Generation X and Gen Y place "way of life" as their top priority, among "achievement" and "supervisory". Baby-boomers rank "way of life" after "achievement" and "altruism".

To review the work values, it is vital to see the overview of the characteristic of all three generations. It is the work of Kupperschmidt (2000) and other related literature review. The study divides into two categories: generational traits, which includes formative years, style, view of money, leisure and technology; and view of work, which includes view of career, rewards, recognition, authority and leadership.

\subsection{A Closer Focus: Millennial or Gen $Y$}

Gen Y or the millennial generation includes those who were born between after 1975 or 1977, (Kim and McClearym, 2010), or these who were born between 1978 and 1988 (Carolyn, 2005).

Sheahan (2005) states that Gen Y is very knowledgeable when it comes to new technology and, thus, Gen Y is used to fast outcomes and results. This has resulted in a personality that lacks patience and tolerance. Thus, 
members of Gen Y will not spend years developing their career. They wish to receive rapid promotion and recognition. Gen Y appreciates a relaxed and creative work place and a style of management that is not too autocratic, and which is no-nonsense and life-style focused. Gen Y is goal and team-oriented and they can be attracted to social and community activities. Correspondingly, Hays Recruitment (2007) has found that Gen Y wants workmates or friends at work, not colleagues. Thus, they are quite communitarian and want to be part of a successful group and team.

Hays Recruitment (2007) also found that members of Gen Y do not like to commence their career at the bottom. They like immediate challenges, recognition and respect. The company they choose must have clear work and career-path planning, so that they have a goal to work towards. Gen Y prefers to work with a company that has a positive reputation, has a brand identity. Gen $Y$ also prefers to work in a meaningful profession. Gen $Y$ wants an intellectual challenge, wants to be successful and wants to make a difference (Eisner, 2005). Additionally, a majority of members of Gen Y expects travel opportunities, training and development, and social events. They do not prefer to sit in the office and process paper; however, they do not mind being in their rooms for long hours searching the internet.

While Gen Y has many positive traits, they are viewed negatively by some mangers in Australia. In a study of 240 Australian business managers, approximately 40 per cent of managers stated that Gen Y is difficult to deal with. Also, 70\% of employers were not satisfied with Gen Y's performance (Casben, 2007 and Preston, 2007). Most members of Gen Y lack communication skills: they have poor spelling, incorrect grammar usage and do not understand what constitutes appropriate corporate behaviour. 37\% of Gen Y lack professional skills and the required technical skills to do their job (Preston, 2007).

If Gen Y does not like their pay, working conditions or the management style, they will move. One year in a job seems to be too long for them. Most managers find Gen Y to be a "headache" because they do not respond to a "do as you are told" management style, as they like to be free, creative and to work under their own authority and autonomy. They prefer to work with a boss who is accessible, capable, ethical and fair. They do not prefer managers who do not use technology. They prefer to work with managers who focus on providing opportunities and incentives at work: they like performance-based types of work and management. They believe that management must show leadership and be creative (Eisner, 2005).

In summary, Gen Y think visually, want immediate gratification, are fun, joyful and enthusiastic. They are not shy in telling others what they want and how they feel. They are well educated, are more tech-savvy than other generations, and they value personal creativity (McGarry, 1999). According to another study, Gen Y prefers close personal connections and looks for relationships with the superiors and colleagues at their work place, as Gen Y values friendship and relationships. Moreover, collaborative, good valuable teamwork, hands-on experience when learning and positive support are imperative for Gen Y (Tice, 2008).

Eisner (2005) also suggests that if a company wants Gen Y to become productive in the tourism and hospitality field, they y should offer multi-tasking and variety, free access to workmates, a voice in the work-placed, project-centred work and constant information via IT tools.

\subsection{Characteristics and Behaviours of Gen Y in Thailand}

As the hotel industry is challenging, especially with respect to its work characteristics and working conditions, reviewing and gaining an understanding of Gen Y's characteristics and behaviours is essential (NationalMaster, 2010).

Though research about Gen Y's behaviour in Thailand is limited, Sinnithithavor (2010) reports that Gen Y are highly technologically capable. Gen Y does not like rules and regulations in the workplace. They love fast decisions and they will resign without extensive though if they are dissatisfied. They are very confident, and they expect a high salary at the entry level, as well as rapid promotion. They love freedom and like to be empowered at work. In the mean time, they prefer mobility and do not like long routine work. Those who have baby-boomers as their management view baby-boomers as antique and not up-to-date and not a very effective management. They therefore do not value seniority. However, they do like to be recognised. They are well educated as many members of Gen Y hope to gain further degree as they believe a good education and degrees are the factors that create a competitive advantage (Thamma, 2009).

Asisonthisakul (2005) has stated that Gen Y performs very well in creative tasks and that they value a friendly working environment. Gen Y likes a participative managerial style and prefers a flexible working schedule. They do not value corporate loyalty; however, they like to work with a company that exercises corporate social responsibility (Srisawak, 2010). 


\section{Methodology}

The objective of this research is to identify Gen Y's preferred working model. In order to identify the working model, the researchers aimed to obtain maximum information, views and thoughts from respondents; thus, qualitative research using an inductive approach involving a focus group discussion method was selected for data collection, with a grounded theory technique.

Students of the Tourism and Hospitality Management Programme (THM), a bachelor level degree at MUIC, Thailand, were chosen as the target participants in this research study (see Table 1). The THM programme requires students to undergo a compulsory three month in-house internship at SPH managed by MUIC.

Table 1. Target participants in this study

\begin{tabular}{llll}
\hline Group & $\begin{array}{l}\text { Students of the THM programme, MUIC, } \\
\text { Thailand }\end{array}$ & $\begin{array}{l}\text { Number of } \\
\text { students }\end{array}$ & Session \\
\hline $\begin{array}{l}\text { Group 1 } \\
\text { (Experienced }\end{array}$ & $\begin{array}{l}\text { Already carried out three month compulsory } \\
\text { internship SPH }\end{array}$ & 33 & October 22, 2012 \\
$\begin{array}{l}\text { Group) } \\
\begin{array}{l}\text { Group 2 } \\
\text { (Inexperienced }\end{array}\end{array}$ & Currently engaged in internship at SPH & 33 & November 6, 2012 \\
$\begin{array}{l}\text { Group) } \\
\text { Total }\end{array}$ & & 66 & \\
\hline
\end{tabular}

The participant students are members of Gen Y with an average age of 20 to 23 years. A totality of 66 students participated. To avoid bias a mix of genders was selected: 20 males and 46 females were invited to attend the focus group session. 33 students (Group 1, the experienced group) had already carried out the three month compulsory internship and had resumed their academic programme.

Another 33 students (Group 2, the inexperience group) were still undergoing practical training. At the time of focus group activity they had already reached the half way point of their three month internship. Two focus group discussion sessions were arranged, at two different times. The rationale for this was that 66 students would be too numerous to carry out a discussion with at one time and discussing the topics with this number would result in a complex conversation during the research participation process. Carrying out the discussion with the two groups at separate times was more effective and offered a higher quality of research. The focus group topic that was freely and openly explored was: "what are the factors or work conditions that will make you most productive and effective, and will ensure you will be loyal to the work and organisation."

Each focus discussion session involving 33 students lasted approximately four hours, totalling eight hours for the two groups of respondents. The sessions included a short break. Snacks were provided to the participants and the sessions took place in a relaxing environment. The focus group discussion was run as follows: the researchers first proposed the topic to the respondents. The topic was: "What were the respondents' preferred working conditions and/or factors that would encourage them to work effectively and to stay longer in a particular organisation". Throughout the session, the respondents were given freedom to talk, to explain, to give examples and to explore their feelings. The researchers asked respondents to illustrate and explain further certain points, from time to time, to make sure the information was well understood. If there any answer was un-clear, the researchers probed further in order to allow maximum information to be provided by the respondents.

Furthermore, the researchers have explained the research purpose and ensured that the discussion environment was fun, friendly and relaxing in order to ensure respondents felt able to express what they wanted to express. Moreover, the explorative topic of the research itself was a fun and interesting one for the respondents to take part in, particularly as the respondents knew that this research was being carried out in order help other generations work better with Gen Y. Thus, the respondents were very cooperative.

As is shown in Figure 1, a grounded theory was used to take approach in the analysis of data. Content analysis was also applied by using a frequency and thematic approach while coding. This stage involved filtering the data and calculating the frequency of a particular anecdote or statement of factors given by Gen Y students. The conceptual data would be used to identify coding stage of its relationship, an axial coding. In this context, the data was grouped or regrouped, to identify its results. Thereafter, the interrelating and integrating the theory would be driven to select a coherent theoretical structure, which allowed us to identify the research findings at this stage. 


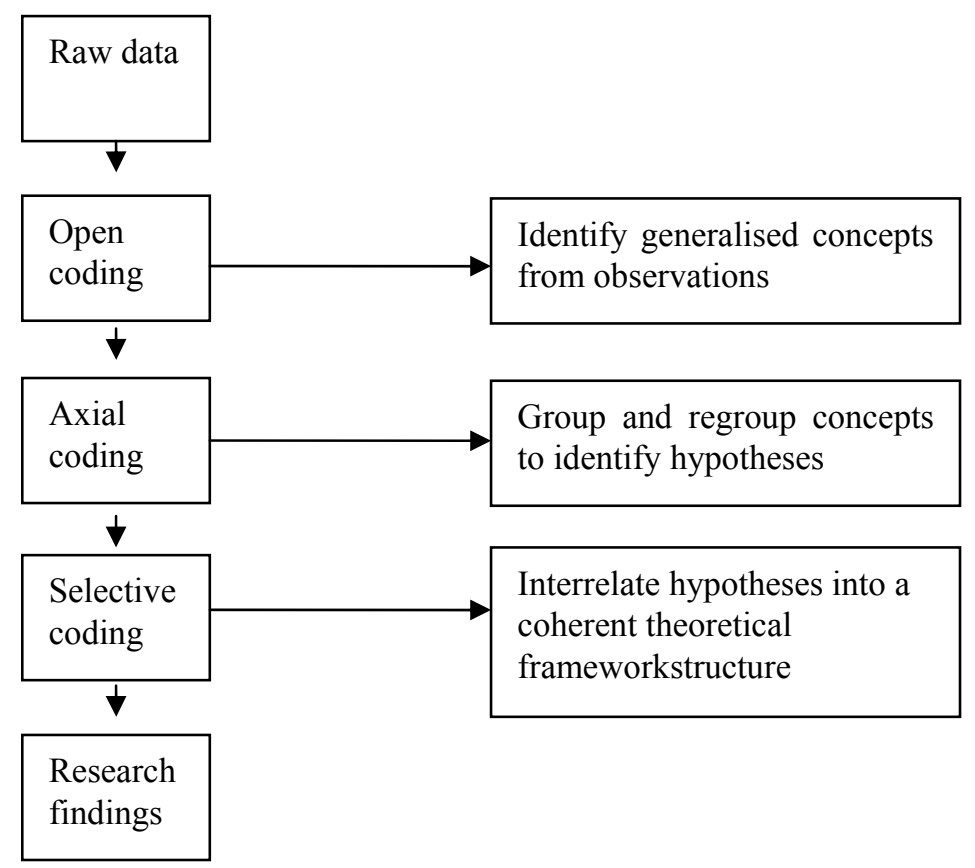

Figure 1. Model of the grounded theory process by Johns and Lee-Ross (1998), p. 136.

To ensure validity and reliability of data, note-taking and tape recording was used during the focus group discussion and, in the interests of confidentiality and ethics, the respondents were informed that the recordings were to be kept only with the researchers and would be deleted after the data was transcribed from the tape recorder to a Word document. Cross-checks between two researchers were also applied during coding, to avoid bias.

\section{Findings and Discussion}

The study findings are noteworthy. The highlights from the findings are as follows: five factors were pointed out by Gen Y respondents in both groups:

1) Leadership

2) Friendly environment

3) Good pay and benefits

4) Flexible policy and an "I-am-valuable" culture

5) Great facilities

Table 2 shows the results and highlights possible differences in respondents' opinion (between the two groups of respondents) towards what influential factors encourage Gen Y to work more effectively and to stay longer with a particular organisation, particularly in the hotel industry.

Category 1: No difference in respondents' opinions. There were a total of 75 comments related to the "leadership aspect". The comments included that a leader must be communicative, friendly, flexible, kind, and fair. Moreover, the respondents stated that, for Gen Y, a leaderGen must be open minded. Remarkably, there was no significant difference between the two groups of respondents. This means that the leadership factor is viewed by Gen Y to be a vital subject. 
Table 2. Comparative on influential factors for Gen Y's work effectiveness of experienced and inexperienced groups

\begin{tabular}{|c|c|c|c|}
\hline Category & $\begin{array}{l}\text { Influential factors for Gen } \\
\text { Y's work effectiveness }\end{array}$ & $\begin{array}{c}\text { Frequency with } \\
\text { which factor } \\
\text { discussed }\end{array}$ & $\begin{array}{c}\text { Differences between two groups } \\
\text { (Experienced group and Inexperienced } \\
\text { group) }\end{array}$ \\
\hline 1 & Leadership & 75 & No difference in opinion \\
\hline 2 & Friendly environment & 109 & $\begin{array}{l}\text { Slight difference ( } 14 \text { comments by } \\
\text { inexperienced group reflected difference } \\
\text { of opinion) }\end{array}$ \\
\hline 3 & Good pay and benefits & 103 & $\begin{array}{l}\text { Slight difference ( } 10 \text { comments by } \\
\text { experienced group reflected difference of } \\
\text { opinion) }\end{array}$ \\
\hline 4 & $\begin{array}{l}\text { Flexible policy and an } \\
\text { "I-am-valuable" culture }\end{array}$ & 64 & No difference in opinion \\
\hline 5 & Great facilities & 18 & No difference in opinion \\
\hline
\end{tabular}

Category 2: Only slight differences of opinion in relation to "friendly environment" factor. In total, 109 comments were made in relation to the kind of working envrionment. The respondents stated that, to be a positive influencing factor, the environment should be nice, harmonious, helpful, relaxing, stress-free, well decorated, clean, fun, challening and healthy. 15 comments related to respondents wanting to sing a song in the work environment, to listen to a song, or to dance during working time. If respondents are in a housekeeping deparpment, they can talk and turn on the TV when cleaning rooms and can eat at work or can sit at work (they do not always need to stand). It is noticeable that only one respondent from the experienced group stated that he wishes to sing a song during working hours. The rest of the 14 comments in this regard were from the "inexperienced group". This suggests that the respondents who have already finished an internship have grown up and have more understanding of the professionalism of service required in their work.

Category 3: There were only slight differences with respect to "Financial compensation", particularly with respect to the non-financial aspect. 33 comments were made about direct financial compensation: these related to good pay. 70 comments related to non-direct financial compensation and referred to benefits like insurance, flexible work schedule, holidays, a career path, promotions, good training and various types of parties. 33 comments about a good, reasonable salary were made consistently across the two groups of respondents. However, of the 70 comments about non-direct compensation ten made by the experienced group discussed team activities like sports days to get to know work colleagues. This reflects the development of the students' understanding after the internship: some students realise that relationships among workers is essential for success in work and they believe that carrying out team work activities can lead to a better team.

Category 4: The 64 comments about a "Flexible policy and an "I-am-valuable" culture" were consistent across the two groups. The respondents commented that they preferred an absence of strict rules and regulations, such as rules relating to uniforms. They stated that management should value people for their quality, there should be no discrimition, no favouritism, no bias, and staff should be treated as an asset. This suggests that Gen Y believes that successful people-management strategies involves a good policy and a culture in which the management respects and recognises their staff as valuable human beings.

Category 5: There was no differrence between the two groups on "Good facilites". There was a total of 18 comments which were consistent across both groups. Good facilities for the respondents mean an internet zone, a staff lounge, a karaoke room, beds for staff, a games room, a pool table, car parking, good lockers and the ability for staff to eat at the hotel outlet. However, the frequency of these comments were not as high as comments about other elements.

As is clear from the above findings, there is almost no difference in the opinion of the two groups of respondents (experienced and inexperienced) with respect tothe influencial factors and preferred working conditions. What differences there are are very slight, as is made clear in Table 2. However, certain critical points require further discussion. These points are Gen Y's environment, Gen Y's preferences with respect to financial compensation, Gen Y's attitude to leadership and lastly Gen Y's valuing of a relaxed policy.

\subsection{Gen Y's Environment}

A friendly environment is on topic that Gen $\mathrm{Y}$ is keen on, as is reflected in the high number of comments (109 comments). The work environment is extremely important for Gen $\mathrm{Y}$ in Thailand. There were up to 42 
comments about a friendly environment and 23 comments about an unstressful and non-competetive atmosphere. The respondents prefer a harmonious life; this is also a Thai way of living. Therefore, their preferrred environment is one that mostly focuses on people: people who create friendliness, harmony, and unstressful feelings while at work, and who are not competitive. The preferred environment will allow and enhance good friendships and relationships at work and, which would thereforee resultin good team work. This finding strongly corresponds with the findings of both Thai and Western researchers like Hays Recruitment (2007), Tice (2008) and Asisonthisakul (2005) that Gen Y places profound importance on connections and relationships in the work place. A highly collaborative group and team work is viewed as a significant factor. A positive team spirit is preferred by Gen Y worldwide, not only in Thailand but also in other countries. This finding is also well supported bythe findings of Adams (2000), Kupperschmidt (2000), Armour (2005), and Martin (2005) in the genertional traits in the view of formative years of generation $\mathrm{Y}$ on their radically diverse. Gen $\mathrm{Y}$ gets along well with others and they are connected to people easily compared to Generation $\mathrm{X}$ as Xers are raised in economic instability and the society at Generation X's time is unfriendly to the children. Gen Y is therefore more people-focused and sociable and thus wants to be part of a team success. Furthermore, the Sheahan's (2005) finding that Gen Y prefers a relaxing work place mirrors the finding of this paper that Gen Y in Thailand likes to work in an environment that is not only friendly but also relaxing and stress-free. If Gen $\mathrm{Y}$ faces too much tension or pressure at work, they believe that they will not be productive.

\subsection{Gen Y's Preference with Respect to Financial Compensation}

The findings show that there were 103 comments on this aspect, meaning financial compensation ranked second after a friendly environment. 33 comments by the Gen Y respondents touched on direct financial compensation (ie salary or wage). The remaining 70 comments refered to various types of non-direct compensation scheme. Furthermore, there were 18 comments discussing team activities, interactive activities, staff parties, birthday parties or sports days. 14 comments related to flexible schedules, 12 comments related to not liking repetitive work, 11 comments to a clear career path and two out of 11 touched on rapid promotion, and some related to having more days off. Thai members of Gen $\mathrm{Y}$ who have less work or training experience therefore like to be interactive with their collegues in an informal setting, such as at parties. This finding suggests that in the initial stage of their work, the management may like to enhance Gen Y's morale by providing a more informal setting for a get-together, rather than an official meeting. Furthermore, Gen Y is quite demanding with respect to their work schedule as they want flexbility and do not wish to do repetitive work. At the same time, Gen Y wishes to have a clear career path with the possibility of fast promotion. All these findings match the findings of Adams (2000), Kupperschmidt (2000), Armour (2005), and Martin (2005) with regard to the genertional traits of Gen Y's view of leisure and of money. Gen Y is fiancially smart and desires a work-life balance. Thus, Gen Y is costly to employ. They also expect rapid promotion and development, are demanding, have high expectations of employers and are goal-oriented. Moreover, they are highly technologically capable. In similar findings, Hays Recruitment (2007) has found that Gen Y is goal-oriented and they wish to have a clear plan of work and career path,and they do not like repetitive work. They do not like to sit in an office and process paper work as they find this boring (Sinnithithavor, 2010). Social corporate responsibility projects could be one way of helping Gen Y not to become bored at work.

McGarry (1999), Adams (2000), Kupperschmidt (2000), Armour (2005), and Martin (2005) add that Gen Y is highly technologically-minded. This is supported by the findings in this research with 11 comments related to requests that a company have an employee lounge with an internet zone.

In a Thai context, the result of this paper finds that although Gen Y likes to be well paid, a similar finding to another researcher focusing on Thailand, Sinnithithavor (2010). 11 comments relate to an expectation of good pay. The results also show that non-direct financial compensation is crucial, compared to direct monetary compensation: there were 14 comments on flexible work schedules and 11 comments on good facilities, like pool tables, DVD games, snacks with beer and wine (together with the internet zone already mentioned). This finding is supported by another researcher in Thailand, Asisonthisakul (2005), who found that Gen Y prefers flexibility in their work roster. However, the Western Gen Y does not discuss flexible scheduling and parties at work in the way that the Thai Gen Y does. Another highlight of the findings was that team activities like sports days, get-together parties, staff parties or birthday meetings may be more important to Thai Gen Y than to Gen Y in other parts of the world. It is noticeable that Thai Gen Y's work satisfaction depends more on non-direct monetary aspects compared to the Western Gen Y; the Western Gen Y may be less demanding. In summary, Thai Gen Y's organisational and work loyalty is not always achieved by high pay; rather it may be obtained by a handsome package of other benefit schemes. 


\subsection{Leadership for Gen $Y$}

The finding shows that leadership is influencial on Gen Y's work fulfilment: there were 75 comments related to this area. Gen Y prefers managers who pay attention, hear and listen to them, canvass their views, and provide them with advice or feedback. Additionally, friendliness and flexibility in a leader is highly important to Gen Y. This mirrors the findings of Asisonthisakul (2005) that Gen Y in Thailand prefers a management style that is flexible and participative. This means the manager should involve the employees: the involvement starts with communication and being friendly to staff. Also, the findings of Adams (2000), Kupperschmidt (2000), Armour (2005), and Martin (2005) on the genertional traits of Gen Y are; active parents, giving feedback and direction. This has meant that Gen Y prefers a boss that is interactive and participative, rather than one who is hierarchical and reserved. However, members of Gen Y in the West may prefer to work with a manager who is accessible, capable, ethical and fair (Eisner, 2005) more than a boss who is communicative and / or a superior who gives constant advice and direction.

\subsection{Gen Y Values a More Relaxed Policy}

There were 64 comments about liking a flexible policy and about preferring to be treated with respect, and to be valued. Gen Y do not like strict rules and regulations such as those related to uniforms and personal appearance. However, in the hotel field, professional grooming is required; this is not always well liked by Gen Y. Generation Y may take pleasure in possible seasonable uniforms; this is something the hotel management team may like to adjust and adopt the finding in their practicality, as long as it is feasible. Moreover, they prefer a company that has a flat organisation policy, that is not too strong on hierarchy and one where their voice is sincerely heard. They wish to put across their ideas and opinions and they want to feel that they are recognised as an important asset in the company. This matches the findings of other researchers: Adams (2000), Kupperschmidt (2000), Armour (2005), and Martin (2005) share the view that Gen Y is confident, displays independent thinking and have a high expectation of themselves. In addition, Gen Y likes to see that their comments and thoughts are valuable. They want to be recognised as a true asset. Sheahan (2005) and Hays Recruitment (2007) support the finding that Gen Y likes recognition and respect. Likewise, a Thai researcher, Sinnithithavor (2010), reports that Gen Y prefers to have few rules and regulations in the workplace: they like to be empowered at work. They are extremely confident, thus they like to exercise their competencies without too much hierarchical instruction. Thai Gen Y views managers from the older generations as being slow in decision-making due to the fact that these managers have many processes for approving decisions because of the strong hierarchical settings in which they work, particularly govermental offices. In the view of Gen Y, this is not effective and leads to under-performance. There may well be a tremendous gap between Gen Y and other generations in this regard.

However, in the hotel setting, In many high profile organisations, there are strict rules and regulation, no compromises about quality of service because standard practices are required by employees. However, presently, many Thai hotels and resort properties have developed a unique theme and a concept of their property into a more of trendy, chic and chill styles to understand customer needs. The hotel standard of such a trendy unit can be different and altered: this means more relaxing, more friendly and less formal during interactions with customers. Thus, it is noticable that most of these businesses with a special theme are associated with Gen Y employees are more satisfied and proud to work for these organisations.

Thus, hotel rules, regulations and standards often depends on the concept, theme and service strategy set whether it will be strict or not. For instance, some hotels are very firm about their employees' hair styles: for example, that they must wear their hair in a bun. In other resorts employees can let their hair down while on duty and can wear a more causual uniform style. This depends on the business concept of the orgnaisation that Gen Y chooses to work with. Nonetheless, in a hotel setting there are a number of rules and regulations that associates must strictly follow, related to food hygiene, cleanliness, safety and security. It is a fact that many procedures and standards of practice can not be avoided by employees, as such employees' performance will reflect the word "quality" of the organisation.

As Gen Y is increasingly occupying a central place in the hotel industry, the industry will increasingly depend on Generation $\mathrm{Y}$ to help develop further. Thus, management that belongs to the baby-boomer generation or to Generation X may wish to adopt some of the recommendations below, related to work paradigms for managing Gen $\mathrm{Y}$ associates, particularly in the Thai hotel industry.

\section{Conclusions and Recommendations}

From this study, one can conclude that undergradutate Gen Y students (both experienced and inexperienced with respect to work) have similar opinions and views towards about what factors encourage them to be more 
productive, effective and loyal to a company. There are slight differences as shown in the results on some development of understanding between the experienced and inexperiened groups. Some students who had already completed a three month internship seemed to have a better understanding about discipline in work conditions and the team spirit needed at work.

Nonetheless, the findings of this study produce the interesting conclusion that compensation is very important for Gen Y associates in Thailand. Mondy et al (2002) have stated that compensation has both financial and non-financial aspects. The financial part is composed of direct and non-direct compensation. Direct means pay and salary; non-direct relates to insurance, medical care, vacations, work schedules etc. Non-financial compensation aspects include the job and the job environment which very much depends on the leadership style. The job aspects means whether leaders provide freedom, feedback, training and make employees' tasks special, and whether they are motivating. While the job environment aspect means, for example, if there are sound policies and a comfortable work enviornment. Non-financial compensation is thus very much dependent upon the management and leadership styles of the managers. Gen Y's needs and wants have been confirmed by Thai researchers: Asisonthisakul (2005), Srisawak (2010) and Sinnithithavor (2010) found that Gen Y in Thailand expects good pay, does not prefer a strict work environment, and believes empowerment and freedom at work are vital. Moreover, flexibility in the work schedule and vacations are somewhat attrating.

The follwing propositions or recommendations are provided to the reader, whether they be academics or practitioners in the hotel industry in Thailand. Academics and practitioners can make use of these recommendation in educating Gen $\mathrm{Y}$ and, if applicable, to recruit, attract, manage and retain Gen $\mathrm{Y}$ associates, particularly in Thailand.

Recommendation 1: A Good Market Rate on Direct Financial Compensation and a Strong Non-Direct Benefit Package. To attract Gen Y, the management of an organisation should establish a market rate compensation strategy with respect to monatery reward, meaning salary and wages. This will be the first stage for Gen Y to consider joining the organisation. However, as Gen Y does not focus solely on good pay, other benefits are also crucial: for instance, a flexible work roster or scheduling, regular get-together meetings or parties, clear career-path planning and more days off per week, to ensure a positive work-life balance. The organisation should make their brand unique by adopting strong benefit packages to attract and recruit Gen Y and by announcing and emphasing these packages publicly. This is one way of increasing the pride and brand loyalty of Gen Y as Gen Y will feel they are well taken care of and are an important asset within the organisation. Therefore, it seems nowadays that hotels invest more to having Gen Y's employees than last decades

Recommendation 2: A Committed Non-Financial Compensation Scheme: Gen Y will be productive and effective if they are in a positive job environment: this will form a non-financial reward. The organisation should create a well-built friendly, helpful and communicative culture. Generation Y will not be able to contribute in the most optimum if they are forced to work in atoo-strict and stressfull atmosphere. The management should enssure that they strive for excellence in creating a team spirit as relationships is an essential element that will enhance Gen Y's productivity. A group reward strategy may be an ideal method of ensuring a strong morale among Gen Y, in certain projects. The management should make sure the culture and policy ensures no discrimination in any respect, and that there is no bias and no favoristism. They should recognise Gen Y staff as an asset: this will be an indispensable culture and policypractice when working with Generation Y. All in all, the work environment is a key non-financial benefit for Gen Y. Towards this end, the balancing the work environment to fit Gen $\mathrm{Y}$ may be something the organisation needs to look into.

Recommendation 3: A People-Oriented Leader: Gen Y's managers should be very well trained in people management. To motivate Gen Y, managers must not be quiet and should not use an hierarchical form of management. On the contrary, the managers should be both guides and true friends who just happen to have more experience than their Gen Y employees. He or she should be excellent in their interpersonal skills, communication skills and influencing skills, and should have a friendly and approachable personality. Participative and flexible management styles are needed when managing Gen $\mathrm{Y}$ associates. Moreover, managers must be sincere in showing respect and providing compliments to Gen Y staff whenever it is needed. Being fair and firm is also essential for managers when dealing with Gen Y employees. A Gen Y manager must love people and like to deal with differences in each human being in order to facilitate and support each staff member to excel. The above-mentioned strategy and tactics would help to retain Gen Y associates and ensurethey stay longer with the organisation. The question a company will ask is how much investment will be needed to ensure the managers fit Gen Y's needs and wants? A pro would be that there may be more development for Gen X and baby boom managers. But will the Gen $\mathrm{X}$ and baby-boomer managers see the need to adjust themselves to fit with Gen Y? And will the training and development investment guarantee the desired outcome? 


\subsection{Recommendations for Future Research}

Any researcher who has an interest in developing people in the hotel and tourism field could gear their research to a group of members of Gen Y who have longer years of experience in the industry, or even those who are at the first stage of a superviory level position. As the finding section has shown in this research, the group of students who have already completed their three month internship at SPH has a slightly better understanding and perception of the professionalism needed in hotel operations, compared to the inexperienced group. Three months is not a long time and it may be possible that longer years of experience may enhance understanding of members of Gen $\mathrm{Y}$ with respect to the hospitality industry. They may be more mature and may better understand the fundamental standards required in the hotel industry. For instance, the demands about singing, eating and watching TV during work, as well as the desire to have regular parties represent the anxieties of the second group who are still pusuing training. Hence, future research on Gen Y hoteliers who have had a longer experience of work may result in another side of the preferred work paradigm for managing Gen Y.

Moreover, further research could use a broader range of sampling; for instance, respondents in another country in Asia or in other continents could be interviewed, in order to discover any possible differences. This piece of research has focused on Thai Gen Y, and on a particular group of students in a hotel and tourism programme. All in all, with this research study, it may concludes that a people-management paradigm, no matter if it relates to Gen Y or others, will be more successful and will flourish if management applies the right strategy and tactics to the right group of employees.

\section{References}

Adams, S. (2000). Generation X: how understanding this population leads to better safety programs. Professional Safety, 45, 26-9.

Armour, S. (2005, November 8). Generation Y: They've arrived at work with new attitude. USA Today.

Asisonthisakul, R. (2005). Prepare your organization for Generation Y. Productivity World (Jan-Feb).

Bares, A. (2011). 2011 Turnover Rates by Industry. Retrieved from $\mathrm{http}: / /$ www.compensationforce.com/2011/10/2011-turnover-rates-by-industry.html

Benckendorff, P., Moscardo, G., \& Pendergast, D. (2010). Tourism and generation Y. Oxfordshire: CAB International.

Boon-itt, S., \& Chomvong, V. (2010). Analyzing Service Quality in Thai Hotel Industry: An Application of the SERVQUAL Model. Proceedings of the 2010 IEEE IEEM (pp 395-399). Thailand: Thammasat Business School.

Casben, L. (Reporter). (2007, July 17). Generation Y disappoints employers. Australian Broadcasting Corporation. Retrieved

from http://www.abc.net.au/news/2007-07-13/generation-y-disappoints-employers/2503196

Crobsy, A., \& Stephen, N. (1987). Effects of relationship marketing on satisfaction, retention, and prices in the life insurance industry. Journal of Marketing Research, 24, 404-411. http://dx.doi.org/10.2307/3151388

Eisner, S. P. (2005). Managing Generation Y. S.A.M. Advanced Management Journal, 70, 4-15.

Gronroos, C. (1990). Relationship approach to marketing in service contexts: The marketing and organization behavior interface. Journal of Business Research, 20, 3-12. http://dx.doi.org/10.1016/0148-2963(90)90037-E

Hays Recruitment. (2007). Portraying generation $Y$. Retrieved October 19, 2012, from http://www.hays.com.au/news/ausworkplace/issue4b.aspx 14

Hinkin, T., \& Tracey, B. (2000). The Cost of Turnover. Retrieved from http://www.lisajacksonnortham.highpowersites.com/f/The_Cost_Of_Turnover_-2000.pdf

Johns, N., \& Lee-Ross, D. (1998). Research methods in service industry management. London and New York: Cassell

Kim, B., McCleary, K., \& Kaufman, T. (2010). The new generation in the industry: Hospitality / Tourism students' career preferences, sources of influence and career choice factors. Journal of Hospitality \& Tourism Education, 22(3), 5-11. http://dx.doi.org/10.1080/10963758.2010.10696979

Kupperschmidt, B. (2000). Multigeneration employees: strategies for effective management. The Health Care Manager, 19, 65-76. 
Kusluvan, S., \& Kusluvan, Z. (2000). Perception and atittudes of undergraduate tourism students towards working in the tourism industry in Turkey. Tourism Management, 21, 251-269. http://dx.doi.org/10.1016/S0261-5177(99)00057-6

Martin, C. (2005). What managers need to know about Generation Y. Industrial \& Commercial Training, 37(1), 39-44. http://dx.doi.org/10.1108/00197850510699965

McCrindle Research. (2010). Snapshot: Australia approaching 'peak labour'. Retrieved October 4, 2012, from http://www.mccrindle.com.au/LiteratureRetrieve.aspx?ID=68075\&A=SearchResult\&SearchID=984506\&O bjectID $=68075 \&$ ObjectType $=6$

McGarry, R. (1999). The coming of the GEN X Bosses-Members of generation X is coming into management jobs, and they differ in several ways from those of the baby boom generation. Entrepreneur. November, 1999.

Mistilis, N., \& Daniele, R. (2000). Education and Australian Government Policy: Delivering Information Technology outcomes for Tourism businesses? Information Technology and Tourism, 3, 3-14.

Mondy, R., Noe, R., \& Premeaux, S. (2002). Human Resource Management (8th ed.). Upper Saddle River, NJ: Prentice-Hall.

NationalMaster. (2010). Thailand Population Pyramid for 2010. NationalMaster. Retrieved March 3, 2011, from http://www.nationmaster.com/country/th/Age_distribution

Parasuraman, A., Zeithaml, A., \& Berry, L. (1985). A conceptual model of service quality and its implications for future research. Journal of Marketing, 49, 41-50. http://dx.doi.org/10.2307/1251430

Preston, M. (2007, August 6). In Who'd hire a Gen-Y? Retrieved October 19, 2012, from http://www.smartcompany.com.au/Premium-Articles/Top-Story/Whod-hire-a-Gen-Y.html

Ritzer, G. (1993). The McDonaldization of Society: An Investigation into the Changing Character of Contemporary Social Life. Newbury Park : Pine Forge Press

Samuel, O., \& Chipunza, C. (2009). Employee retention and turnover: Using motivational variables as a panacea. African Journal of Business Management, 3(8), 410-415.

Sheahan, P. (2005). Generation Y; Thriving and surviving with generation Y at work. Melbourne: Hardy Grant Books.

Sinnithithavorn, T. (2010) Generation Y. Retrieved September 3, 2011, from http://sites.google.com/site/490880tippawansinnititaworn/examination/generation- y

Smola, K., \& Sutton, C. (2002). Generational differences: Revisiting generational work values for the new millennium. Journal of Organizational Behavior, 23(4), 363-382. http://dx.doi.org/10.1002/job.147

Solomon, R., Surprenant, C., Czepiel, A., \& Gutman, C. (1985). A role theory perspective on dyadic interactions: the service encounter. Journal of Marketing, 49, 99-111. http://dx.doi.org/10.2307/1251180

Thai Hotels Association. (1991). Annual report. Bangkok, Thailand.

Thamma, Nivat. (2009). GEN B, GEN X, GEN Y: The Power of Generation. Guru Marketing -Thailand. Retrieved March 2, 2011, from http://guru-marketing-thailand.blogspot.com/2009/05/gen-b-gen-x-gen-y-power-of-generation.html

Tice, W. (2008). Leading Generation Y: A mindful approach to retaining employees. Harvard Business Review, 63-73.

Warhurst, C., Nickson, D., Witz, A., \& Cullen, M. (2000). Aesthetic Labour in Interactive Service Work: Some case study evidence from the 'new Glasgow'. Service Industries Journal, 20(3), 1-18. http://dx.doi.org/10.1080/02642060000000029

Zemke, R., \& Schaaf, D. (1989). The Service Edge: 101 Companies that Profit from Customer Care. New York : American Library .

\section{Copyrights}

Copyright for this article is retained by the author(s), with first publication rights granted to the journal.

This is an open-access article distributed under the terms and conditions of the Creative Commons Attribution license (http://creativecommons.org/licenses/by/3.0/). 